\title{
Search for linear measures to estimate the anatomical composition of the carcass
}

\author{
J. NAVEAU \\ I.T.P., Centre expérimental de Sélection porcine, \\ Maxent, 35380 Plélan-le-Grand (France)
}

The purpose of this study was to verify in French conditions, the conclusions of Professor de Boer's report concerning estimation of carcass composition by simple linear measures.

Measurements were made according to de Boer's method on 323 pig carcasses in the Stations of Mauron and Le Rheu.

The results obtained are in agreement with those of Zeist. Prediction equations of muscle and fat weight of the carcass were established. The accuracy of these equations was $R^{2}=0.82$ for muscle weight and $\mathrm{R}^{2}=0.85$ for fat weight.

\section{Estimation of the anatomical composition of pig carcasses and of different cuts}

\section{I. - Establishment of fatness indexes \\ II. - Classification according to indexes}

\author{
B. DESMOULIN (1), P. GRANDSART $\left({ }^{2}\right)$ et J. P. VILA $\left({ }^{3}\right)$ \\ (1) Station de Recherches sur l'Elevage des Porcs \\ I.N.R.A.-C.N.R.Z., $7835^{\circ}$ Jouy-en-Josas (France) \\ (2) I.T.P.-M.N.E., I49, rue de Bercy, 75579 Paris Cedex I2 \\ $\left({ }^{3}\right)$ Laboratoive de Biométrie \\ I.N.R.A.-C.N.R.Z., $7835^{\circ}$ Jouy-en-Josas (France)
}

\begin{abstract}
The present study deals with the estimation of carcass fatness in 126 pigs of various genotypes, sexes and nutritional statuses. Eight sites of backfat thickness (easily approachable variables) were used to establish fatness indexes supplying information about the accurate references of the overall fat content (uneasily approachable variables).

I) In practice, optimum prediction of fatness by means of a simplified procedure involve use of either two lateral measures taken at a distance of 4,5 and $8 \mathrm{~cm}$ from the vertebral column (index $1.65 P_{1}+P_{3}$ ) or two measures on the split at the level of loin and neck (index ${ }_{1.08} \mathrm{ER}^{3}$ + I.06 EC). The specificity of the indexes was due to their high prediction value of the weight and distribution of fat.

2) Segmentation of the variation of each index into 5 classes allowed to establish a classification according to the index in close relation with the fatness references of each group; the latter were characterized by the uneasily approachable measures (backfat weight, flare-fat, specific gravity of belly). The linear segmentation of the indexes might be further changed in order to obtain the best within-group homogeneity. The limits between classes established according to indexes represented a better sorting of fatness classes than that resulting from use of the loin /back maxima (CEE index).

3) For 2 classes of carcass weights $(70-79 \mathrm{~kg}$ and $80-89 \mathrm{~kg})$ the variation of measures and of fatness indexes was studied in relation with the limits of muscle content classes established by the CEE grade. The results obtained were the following :

a) Correction of backfat thickness in relation to $a+10 \mathrm{~kg}$ rise in carcass net weight varied according to the sites of measurements. It appeared to be irregular at the level of the neck and
\end{abstract}


the lateral site $P_{1}$ (from o to $\mathrm{I} \mathrm{mm}$ for carcasses with $40 \%$ muscle to $2-3 \mathrm{~mm}$ for those with $55 \%$ muscle). There was a more regular progression $(2 \mathrm{~mm})$ at the level of the loin and at the lateral site $\mathrm{P}_{3}$ for the same classes of muscle contents.

b) As regards the utilisation of combined measures according to indexes, maximum corrections according to carcass weight did not exceed $3 \mathrm{~mm}$ for the individualized sites; corrections were minimum ( $\mathrm{I} \mathrm{mm}$ ) in the case of very fat pigs.

Modification of a fatness grade has to be related to the progression of backfat thickness measures made for the sites considered in each index; application of these results might contribute to an important improvement of the CEE classification of pig carcasses.

\title{
IV. - Pathology
}

\section{Identification of two outbreaks in France of congenital tremor in piglets and first etiological studies}

\author{
J. P. TILLON (1), J. M. GARRAU (2), P. VANNIER ('), \\ G. PERRIN ( $\left.{ }^{3}\right)$, J. PITRE ( $\left.{ }^{4}\right)$ et P. DROUIN (a) \\ (1) Station de Pathologie porcine, B.P. no 9, 22440 Ploufragan (France) \\ (2) Cabinet vétérinaire, Chemin Saint-Roch, 6r200 Argentan (France) \\ ${ }^{(3)}$ Laboratoire de la D.S.V. des Côtes-du-Nord, \\ 8, place du $74^{\mathrm{e}}$ R.-I., azooo Saint-Brieuc (France) \\ (4) Laboratoire départemental et régional de Biologie et d'Hygiene, \\ 36, nue Fred-Scamaroni, B.P. $n^{\circ}$ 303, I4ooo Caen (France) \\ (5) Ucanor, 14650 Carpiquet (France)
}

Two outbreaks of congenital tremor in piglets with lesions of cerebellar hypoplasia were identified in France. No lesion of the spinal cord was recorded. The presence of neutralising antibodies against the strain 33 $\mathrm{r}$ of SwinejFever in the sera of colostrum deprived piglets showing congenital tremor suggests an etiologic role for a virus of this type.

\section{Immunization of piglets during the postnatal period}

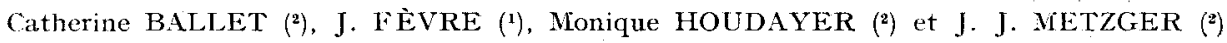 \\ (1) Staion centrale de Physiologie animale, \\ I.N.R.A.-C.N.R.Z., 78350 Jouy-en-Josas (France) \\ (2) Station de Vivologie et d'Immunologie \\ I.N.R.A., 7885o Thivernal-Grignon (France)
}

The ability of young piglets to be immunized during the postnatal period was studicd. The piglets were injected on day o, I, 2, 3, 4, 5, 7 or ro after birth with Hen-Egg white Lysosyme, an inert antigen, in incomplete Freund's $A$ djuvant and the seric antibodies were checked at weekly intervals. The results showed that animals injected within the first 3 days following birth showed a delay of 8 days in the appearance of the humoral antibodies, compared with animals injected later. The secondary immune response was similar in all animals. This partial inhibition is not directly linked to the corticoids present in the serum on the immunization day. Possible reasons for this impairment of the humoral immune response are revieved. 